\title{
Construction supervision at the facilities renovation
}

\author{
Azariy Lapidus ${ }^{1, *}$, and Dmitry Topchiy ${ }^{1}$ \\ ${ }^{1}$ Moscow State University of Civil Engineering, 26, Yaroslavskoye Shosse, 129337, Moscow, Russia
}

\begin{abstract}
Article justify the need for a systematic approach to the formation of uniform requirements for the volume and level of construction supervision carried out in the conversion of industrial facilities. Author determines the factors that affect the safety, is the quantitative characteristics of various types of control measures carried out by specialists of state construction supervision both at the facility and in the office. As a hypothesis, author considers the possibility of forming a single deterministic system that provides objective supervision during the conversion and does not create an excessive burden for both the state and the developer. As a result, the existing legislation in the field of state construction supervision is incomplete and partly contradictory. In this article the necessity of formation of scientifically grounded hierarchical organizational and technological system of construction supervision is defined.
\end{abstract}

\section{Introduction}

The primary risk (or rather, man-made risk) associated with the exploitation of the products of construction industry is such a condition (technical, physical) of the objects of capital construction, which may lead to material, social and environmental losses or risks of manifestation of these consequences in the form of accidents or damage.

The account of the possible manifestations of negative consequences associated with the operation of construction projects is based on the quantitative and qualitative indicators that characterize such features of functioning (or properties) of the considered objects of research as "reliability" and "safety". Formation of conditions for the safe and reliable operation is a priority for the objects of capital construction of any functional purpose.

Despite the increase of the level of technology of construction processes and the efforts of professionals to improve the regulatory framework, there has been an increase in the number of accidents on construction sites, as well as the severity of their consequences [1].

\section{Methods}

The concept of the construction control system involves the use (for evaluation, organization and management of production and non-production processes of interaction

\footnotetext{
*Corresponding author: aljurgaitis@gmail.com
} 
between the structural elements of the system) methods and techniques of system analysis, characterized by the following features:

- system approach is used to analyze only systems;

- obligatory hierarchical approach and multilevel (iterative) nature of the analysis of the subject of research;

- analysis of the mechanism of integration and influence of structural elements in the complex of structural elements and complexes on the end result of the functioning of the system;

- orientation of research to obtain quantitative characteristics that determine the behavior or condition of the system.

\section{Methods and techniques of system analysis}

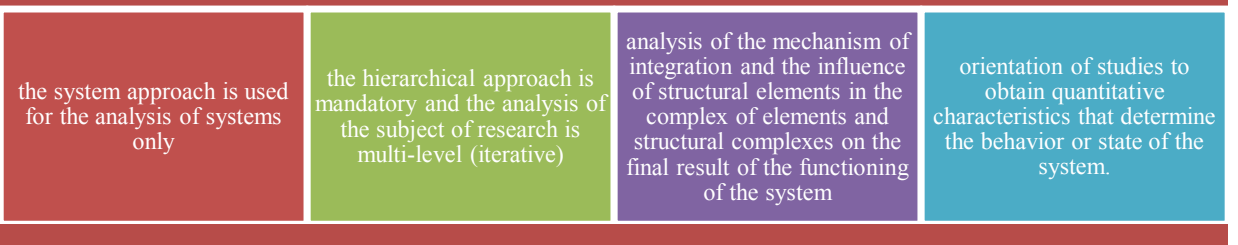

Fig. 1. Methods and techniques of system analysis.

In the adopted formulation, the analysis of the system of building production is considered as a complex polihraftechnica and a hierarchical system consisting of an aggregate of less complex subsystems (systems, components). Each of these subsystems can be considered as an independent object of research.

The consequences of accidents include: direct economic losses (damage), the shortfall in the profit because of the late commissioning (or loss of part of the calculated capacity) of the construction projects, excessive operating costs; premature physical and moral wearout of construction products, reduction of social and/or environmental conditions. The main causes of accidents are the negative factors of different physical nature, which are formed by or manifest themselves at different stages (periods) in the life cycle of construction projects. Analysis of accidents happened at the objects of capital construction (of various functional purposes) indicates that the situations caused by accidents are almost never caused by the consequence of the only one reason and occur as a result of interaction of several different factors (or groups of negative factors). Each of these factors individually may not lead to the accidental consequences, but combined with other adverse factors (which may be formed at earlier stages of the life cycle) lead to accidental impacts. The total number of (presently known) individual adverse factors is large enough. It is evident that over time (with an increase of requirements to functional indicators and methods of forming construction products) the number of individual factors will only increase. In the most general case, under the result of adverse factors (or groups of negative factors) the quality of construction products can be degraded (partialy or completly). [2]

For example, the accident may involve loss of quality which excludes conditions for normal operation of the building object on its initial function. The presence of defects and damages in the constructive system of engineering networks and equipment is characterized as a partial reduction (partial loss) of the quality of the acomplished construction of the facility, which leads to an increase (or contributes to manifestation) of material costs required for the maintenance (repair) of the required performance indicators.

The task of ensuring the quality of construction products implies adequate improvement of the scientific bases, systemic approach, quality management (including monitoring and control) of the of capital construction objects erection. Construction products in the format 
of buildings and constructions is an object environment of extended (long-term, lifetimedefined) period of use. The extent to which the actual reliability and operational efficiency of the finished construction projects correspond to design and regulatory (legislative acts) values, determines the quality of construction products. The quality construction is one of the key factors determining the viability and prospects of development of this field of economic activity (economy). Ensuring reliability and quality is a permanent challenge for the subjects of investment activity in the construction industry [3-9].

Improving the quality of construction products is a complex, multifactorial challenge possible with a use of systematic approach along the following main areas (for key subjects in the investment activity in construction):

- improving conditions for the development and effective functioning of the public forms of influence and intervention in the following formats:

- rationing;

- standardization;

- certification;

- licensing;

- $\quad$ state expertise;

- $\quad$ state supervision.

- formation of the necessary conditions for the effective functioning of the non-state forms of influence and intervention in the following formats:

- internal, production control on the part of the contractor;

- architectural supervision by the project organization;

- technical supervision by the customer;

- construction quality control on the part of the investor

(insurance companies, banking enterprises, private entities).

Quality of construction products (in the formats of indicators of functional efficiency and reliability) is projected, formed and provided for each of the periods of the life cycle.

\section{Results}

Table 1 shows the structure of factors and criteria for the level of quality of construction production. The level of quality largely determines the state (indicators) of competitiveness and is the main factor for the cost of construction products [3].

Table 1. The structure of factors of influence on construction quality.

\begin{tabular}{|l|l|}
\hline \multicolumn{2}{|c|}{ Determinants of quality of construction production } \\
\hline \multicolumn{2}{|c|}{ Regulations and legislative acts } \\
\hline - Construction production technology & - Efficiency of control of performance of \\
- Organization of construction production & standards and regulations \\
- Standard of organization & • Quality of design solutions and project \\
- Quality assessment and control system & documentation \\
- Qualification of management personnel & - Quality assurance of building production \\
- Qualification of construction personnel & - Cost of construction products \\
- Material and non-material factors of & - Conditions of financial and material support of \\
quality stimulation and development & construction production \\
\hline \multicolumn{2}{|c|}{ Quality of performance of construction and installation works } \\
\hline Economic criteria of quality level & Org. and technical criteria of quality level \\
\hline - Cost of construction production & - Reliability of the finished construction project \\
- Level (value) of operating costs before the & - Finished construction project safety \\
first repair & - Risk minimization of manifestations of \\
- Duration & defects, damage to structural elements or fatigue \\
- Duration of the operating period (lifetime) & processes in materials \\
\hline
\end{tabular}


Accordingly, the establishment of conditions to achieve the quality of construction products (taking into account possible changes in the provisions of normative and legislative acts) is a complex task. The effective solution of this task is possible under the condition of a systematic approach to the organization of interaction between the main subjects of investment in construction: "The quality management is the establishment, maintenance and support of the required level of product quality in its development, production and operation, carried out through systematic quality control and a targeted impact on factors affecting quality."

The system approach to quality management of construction products implies the development, approval and execution of a set of measures (technical, technological, economic, organizational work) that accompany the processes of construction. The development of measures to improve the quality of construction products is carried out in the following main areas:

- timely introduction of changes and additions to the composition of project documentation;

- actualization of provisions of normative and legislative acts;

- development of new types of regulatory documentation that takes into account the current and prospective level of the technological state of the system of construction production;

- improvement of training and enhancing the skills of engineering and construction staff.

Quality management of construction products can be represented in the form of a functional system in which the functions (forecast, planning, organization, control, accounting, analysis, examination, evaluation, licensing, certification) can be considered simultaneously: both as a process and as a result. The function considered as a process is a special kind of management activity and a way of influencing the quality of construction production. The function considered as a result represents an assessment of the level of quality of construction products by the following groups of indicators [4]:

- rates of purpose;

- indicators of destination;

- indicators of reliability and safety;

- indicators of comfort, ergonomics and environmental friendliness of the environment;

- aesthetics rates;

- technology rates (during erection and operation);

- rates of unification, availability of manufacture;

- information and legal rates;

- economic rates;

- social rates.

The quality level of construction products is expressed by a system (calculated combination) of single (absolute) indicators and / or complex relative index (the ratio of the complex index of quality of construction products to the corresponding complex indicator of the base level) [5]. The quality management is part of a single and integral system for managing construction production and is implemented at each of the possible levels: state, departmental (industrial), production (object). Quality assessment is an indispensable element of any level of management of the product quality system. At the state level, it is envisaged: planning the necessary indicators and supervising compliance and developing measures to improve the quality of construction products. Planning the quality of construction products is reduced to the development of regulatory and legislative acts regulating the composition, volume and quality of work and activities performed during the main periods of the life cycle, as well as the establishment of technical conditions for the 
manufacture of building materials, products and structures [6]. Presented an opportunity to construction of product quality system in the form of an algorithm (Fig.2).

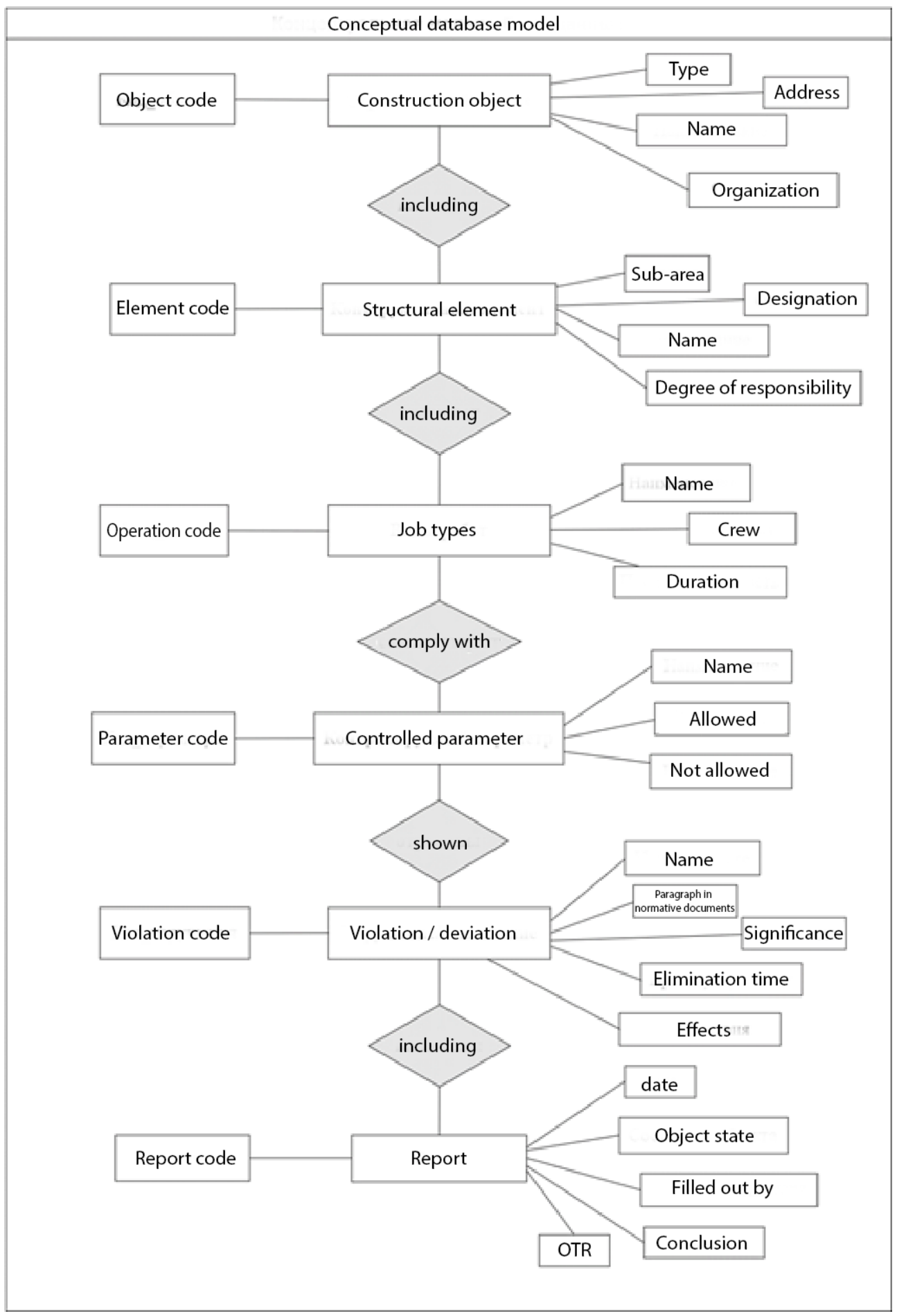

Fig. 2. Conceptual database model. 


\section{Conclusion}

Thus, the hierarchical dependence of the construction supervision in the quality control of construction products (set in the project documentation), which is reduced to three types of inspections (office, field and tool), is formulated. The main requirements for the results of compliance checks carried out by the supervision of compliance with safety rules in the performance of construction works and technological processes, as well as fire, sanitary epidemiological and environmental supervision.

In addition, the result of quality management by the state construction supervision formulated four resulting vectors: constant, relevant, complete and objective assessment of compliance and issuance of recommendations necessary to ensure the established level of quality, regardless of the interests of any subject of investment in construction [7].

Based on the above, it should be concluded that the modern approach to the activities of construction supervision based on the criteria of risk-based approach should be the basis for improving the quality and safety of construction products at all stages of its formation.

\section{References}

1. A. Lapidus, I Abramov, E3S Web of Conferences 33 (2018)

2. D. Topchiy, V. Skakalov, A. Yurgaitis, International Journal of Civil Engineering \& Technology (IJCIET) 9(1), 85-993 (2018)

3. S.V. Korniyenko, N.I. Vatin, A.S. Gorshkov, Magazine of Civil Engineering 64, 10 25 (2016) doi:10.5862/MCE.64.2

4. D. Topchiy, E. Kochurina, System technologies 1 (26), 107-111 (2018)

5. D. Topchiy. V. Skakalov, Prospects of science 10 (97), 44-50 (2017)

6. V.A. Pukhkal, A.B. Mottaeva, Magazine of Civil Engineering 81 (5), 203-212 (2018) doi: 10.18720/MCE.81.20

7. D. Topchiy, A. Tokarskiy, MATEC Web Conf. 196, 04029 (2018)

8. S. Rinaldi, A Flammini, M. Pasetti, L. C. Tagliabue, A. C. Ciribini, S. Zanoni, 2018 IEEE International Instrumentation and Measurement Technology Conference (I2MTC), 14-17 May 2018, Houston, Texas, USA (2018). DOI: 10.1109/I2MTC.2018.8409740

9. M. Scheffer, M. Konig, T. Engelmann, L. C. Tagliabue, A. L. C. Ciribini, S. Rinaldi, M. Pasetti, 2018 IEEE International Workshop on Metrology for Industry 4.0 \& IoT,16-18 April 2018, Brescia, Italy (2018). DOI: 10.1109/METROI4.2018.8428349 